\title{
Optic nerve avulsion: A case report
}

AKADÉMIAI KIADÓ

Developments in Health Sciences

$3(2020) 3,72-76$

DOI:

$10.1556 / 2066.2020 .00013$

(c) 2021 The Author(s)

\section{CASE REPORT}

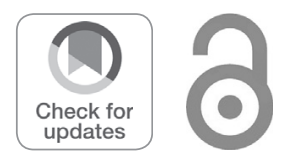

\section{A. GYENES ${ }^{1}$, G.L. SÁNDOR ${ }^{1}$, B. CSÁKÁNY ${ }^{1}$, ZS. RÉCSÁN ${ }^{1}$, G. RUDAS ${ }^{2}$, Z.Z. NAGY ${ }^{1}$ and E. MAKA ${ }^{1}$}

${ }^{1}$ Department of Ophthalmology, Semmelweis University, Budapest, Hungary

${ }^{2}$ MR Research Center, Semmelweis University, Budapest, Hungary

Received: May 05, 2020 • Accepted: February 19, 2021

Published online: March 11, 2021

\begin{abstract}
A case of a 13-year-old girl after being injured on the left eyeball by a stick from a cage, is presented. Along vitreous haemorrhage, retinal oedema and ischaemia, the disc was replaced by a cavity. Multimodal imaging was performed, which confirmed the optic nerve damage. The eye had no light perception anymore. Our case is a demonstration for complete avulsion of the optic nerve after blunt injury.
\end{abstract}

\section{KEYWORDS}

optic nerve, avulsion, injury

\section{INTRODUCTION}

The optic nerve is the second cranial nerve which is formed by the axons from the retinal ganglion cells. It becomes myelinated as it traverses the lamina cribrosa sclerae. Posterior to the sclera, the optic nerve extends from the eyeball to the orbit and becomes enveloped in meninges consisting of three layers: dura mater, arachnoid, and pia mater. The nerve leaves the bony orbit via the optic canal, passes through the optic chiasma, and then terminates in the occipital lobes. It can be divided into extracranial and intracranial components. The extracranial part can be divided into intraocular and intraorbital sections [1,2]. The intraorbital portion of the optic nerve is attached to the dura of the optic foramen. Because of its mobility, usually the extracranial portion of the nerve is involved. Optic nerve injuries caused by a blunt trauma commonly occur at the optic foramen where the nerve enters the optic canal.

Optic nerve avulsion is a rare but possible injury after orbital damage due to head trauma with or without fracture. Avulsion means "extraction by force". It is derived from the Latin verb vellere, meaning "to pull", along with the prefix "e" or "a", meaning "out". If the avulsion is complete, optic nerve and lamina cribrosa together will move backward inside the dural coverage [3]. Sometimes the avulsion can be incomplete, where the nerve will move backward only partly, leaving its dural coverage in its place. Avulsion of the eyeball means a complete separation of the optic nerve from the globe with or without the external eye muscles [4].

\section{CASE REPORT}

*Corresponding author. Department of Ophthalmology, Semmelweis University, Mária utca 39, Budapest, H-1085, Budapest, Hungary. E-mail: drgyenesandrea@gmail.com
A case of a 13-year-old girl is presented. She was admitted to our department after suffering a blunt injury to her left eyeball. The circumstances of the injury are partly unclear. She kept parrots, sometimes she also climbed into their giant unprepared cage. While sitting and playing in the cage, a metal stick fell down from the cage and hit her left eyeball. She lost her vision immediately after the trauma. At her admission there was no light perception on the left eye. Partial-thickness lower eyelid injury with vertical length of $10 \mathrm{~mm}$ could be observed and she also had foreign body sensation on her left eye. Performing examination with a slit lamp, a 
conjunctival laceration could be seen on the inferior bulbar conjunctiva (Fig. 1). Red blood cells hanging in the anterior chamber could be seen, without severe, layered hyphema. Pupil was mid-dilated and there was no direct light reaction on the left side. Lens was clear and its place. There was vitreous haemorrhage in the center originating from the optic nerve head. Peripheral retina was ischaemic, in its place. Other details could not be evaluated. The right eye was unaffected, the best corrected visual acuity was 1.0 with no differences in the ophthalmological status. Magnetic resonance imaging (MRI) and computed tomography (CT) of the skull and ultrasound examination of the eye were performed. Intraocular haemorrhage, peri- and retrobulbar haematoma were found, but the exact location of the optic nerve could not be evaluated (Fig. 2). Local and systemic antibiotic (875/ $125 \mathrm{mg}$ of amoxicillin/clavulanic acid) and corticosteroid therapy ( $80 \mathrm{mg}$ of intravenous methylprednisolone in a decreasing dose) were initiated. The eyelid injury did not require surgical intervention. The intravitreal and peribulbar haemorrhage disappeared within one week, the status of the retina and the disc became visible by funduscopy. The disc

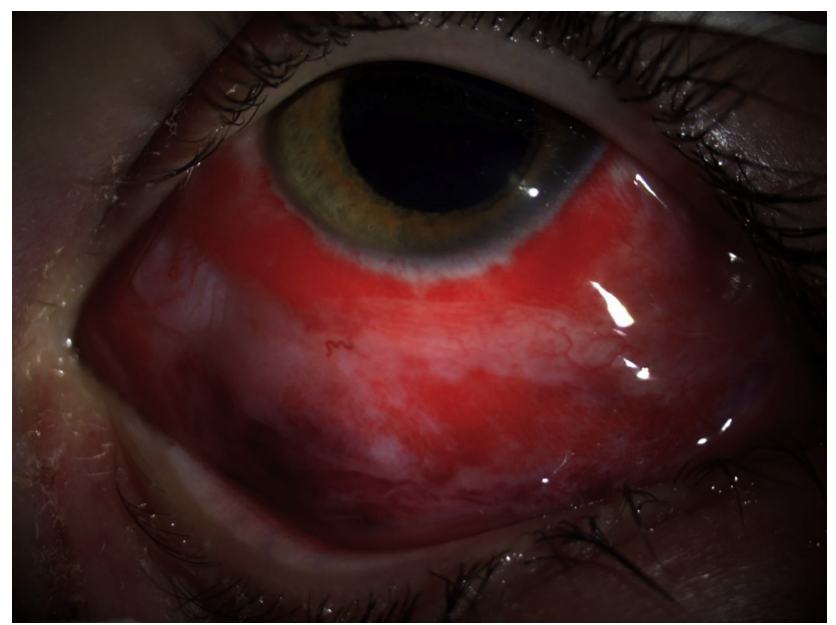

Fig. 1. Slit lamp examination: suffusion, chemosis and laceration of the inferior bulbar conjunctiva was replaced by a hole surrounded by an area of apparentlybared sclera and peripapillary ischaemia and atrophy (Fig. 3). The avulsion of the optic nerve could be depicted by optical coherence tomography (Fig. 4). A circumscribed, flat detachment with an atrophic round hole was visible in the upper quarter of the retina. Reexamination via MRI showed an optic nerve injury on the left side.

Six weeks after the injury, fibrotic tissue began to fill the cavity of the disc. Fig. 5 shows the gliotic connective tissue covering the disc and radiating towards the center of the vitreous cavity five months after the injury. The status of the peripheral retinal detachment remained unchanged. By this time, visual acuity did not recover, the left eye had no light perception anymore.

\section{DISCUSSION}

A case of an optic nerve avulsion was first mentioned by His in 1856 from a histopathological sample [3]. In 1884

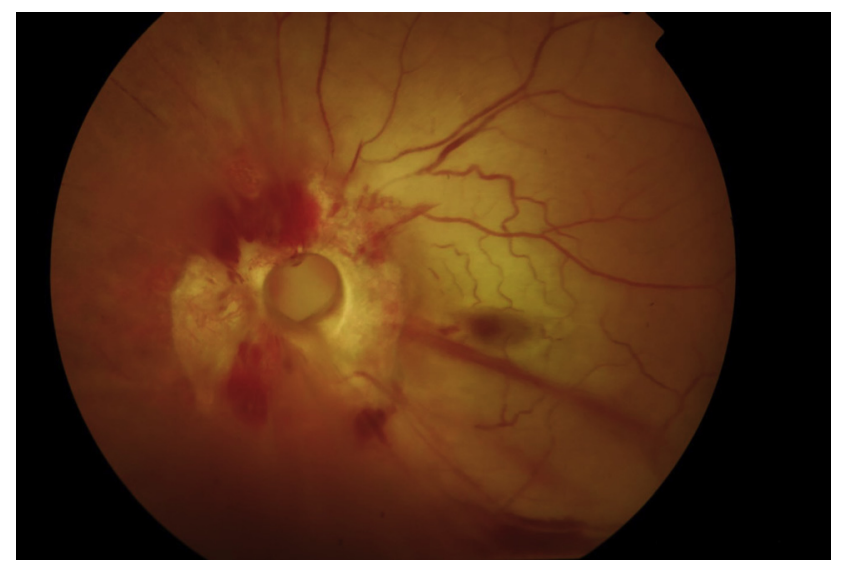

Fig. 3. Funduscopy two weeks after the injury: Optic nerve head avulsion with haemorrhage extending from the disc into the vitreous cavity. A hole can be seen at the site of the disc surrounded by an area of apparently-bared sclera. Retina is ischaemic, blood column is segmented in vessels

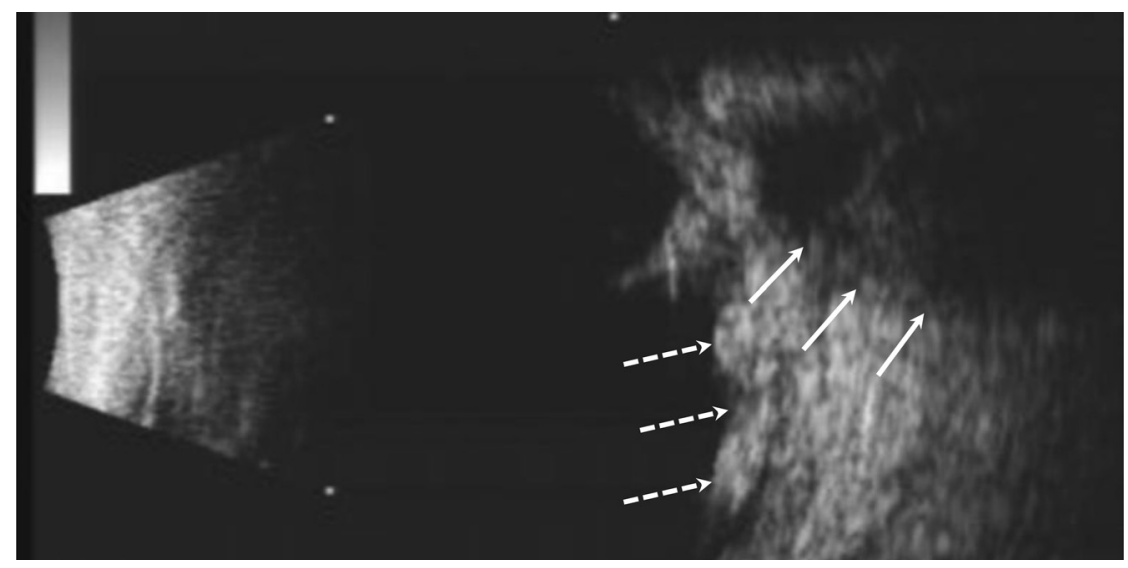

Fig. 2. Ultrasound examination: a hyporeflective area in the localization of the optic nerve from haemorrhage (continuous arrows). The posterior wall of the globe is irregular (dotted arrows) 


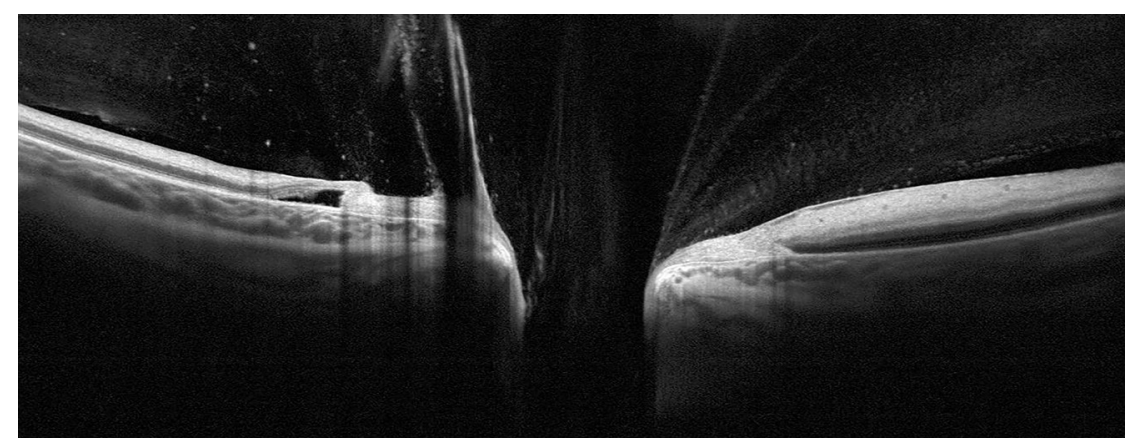

Fig. 4. Optical coherence tomography: cavity at optic nerve head section

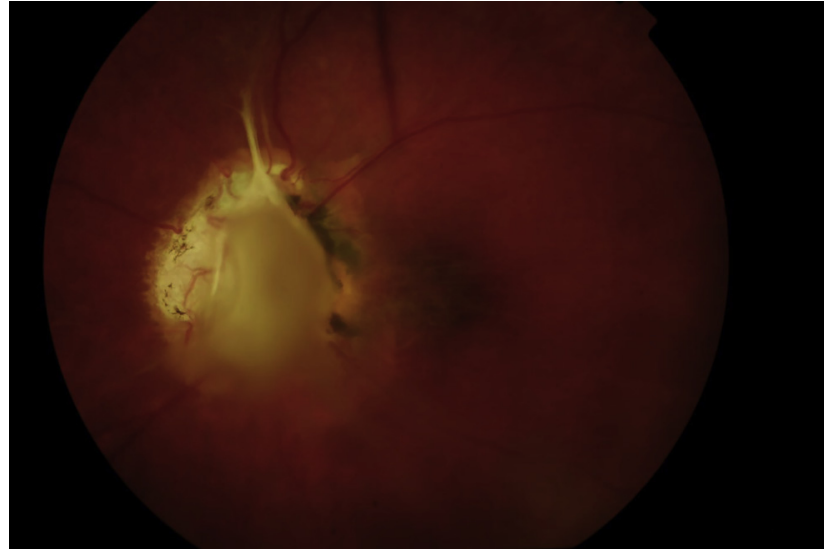

Fig. 5. Funduscopy five months after the injury: Fibrotic tissue covering the atrophic disc and radiating towards the center of the vitreous cavity

Aschmann described the first case of a complete, afterwards Lang a partial optic nerve avulsion [3]. The first full clinical description of complete avulsion was described by Salzmann in 1903, who named the condition 'Evulsio nervi optici' [3].

In 1981, Gross [5] reported that frontal loading can result in the deformation of the ipsilateral orbital roof near the optic foramen and that such deformation of the orbital roof could damage the optic nerve. Retinal ganglion cell (RGC) axons are immediately sheared, haemorrhage of the supporting vasculature and oedema within the sheath covering the nerve are present, which lead to the functional loss.

There are various mechanisms discussed in the literature leading to the damage of the optic nerve with loss of function. From the forced acceleration of the head, the globe moves forward which can lead to the stretching of the optic nerve [3]. Due to a hit on the eyeball, the sudden increase of the intraocular pressure pushes the optic nerve off from the lamina cribrosa like a cork from a bottle $[6,7]$. From rotation, fibres on the contralateral side to the direction of rotation will be sheared $[8,9]$. Sudden increase of intraorbital pressure results in the globe moving forward and the hyperextension of the optic nerve which lead to tearing fibres in the optic nerve $[7,10]$. When projectile or sharp objects injure the optic nerve directly, these cases are diagnosed as direct traumatic optic neuropathy [11]. Foreign body in the orbital cavity can toss off the globe from the optic nerve [12, 13]. Direct and indirect mechanism of injury can possibly lead to the damage of the optic nerve $[6,14]$.

According to retrospective analysis of several case reports Buchwald reported the frequent causes of complete and partial avulsion. Hit with a stick, finger or hand (especially when playing basketball) and traffic accidents were the main mechanisms of the serious injuries resulting in optic nerve avulsion [15]. Severity of the optic nerve injury can be various from contusion to complete avulsion followed by sudden visual loss $[16,4]$.

In cases of partial injury the mean visual acuity was 0.3 decimal after weeks of recovery. Half or quarter of the whole visual field was affected, corresponding to the site of the optic nerve injury. Complete and partial avulsion of the optic nerve were reported by Hidasi [17]. Incomplete avulsion was diagnosed at a 9-year-old girl, who was kicked on her eyeball by her brother. After 2 months her visual acuity recovered to 0.2 decimal and resulted in a visual field loss in the upper half of the visual field demonstrating visual recovery in cases of incomplete injury [17].

Before the advent of radiology modalities, without enucleation or autopsy, the avulsion of the optic nerve could not be exactly diagnosed. Intracameral and intravitreal haemorrhage usually make the diagnosis difficult and the late stage may be misdiagnosed as developmental anomaly $[18,19]$. The ultrasound imaging is useful in detecting the optic nerve damage as an increase in its diameter, but it may be found to be normal $[10,12,20]$. In the majority of the cases the fluorescein angiography shows a complete loss of perfusion in retinal vessels $[8,10,20]$. There are a few cases of optic nerve avulsion where the perfusion remains in the retinal vessels. It can be because vessels have higher tolerance against stretching stimulus, than nerves [7, 21, 22]. At least one week after the injury recruiting perfusion of the retinal vessels from choroidal vasculature can be detected $[23,24]$. CT is a diagnostic tool to exclude fractures in the optic canal and visualize the direct optic nerve injury, even in incomplete cases [25]. The role of MRI in the initial diagnosis is limited because only the fluid accumulation caused by oedema and haemorrhage can be depicted [26]. In most cases, testing with visual evoked potentials (VEP) is not needed to establish the diagnosis. However, in questionable cases, VEP may have predictive value. Patients with better 
VEP responses may be more likely to regain some of their vision $[27,28]$.

Following the primary insult from head injury, secondary mechanisms may lead to further damage of the optic nerve, which should be targeted by treatment options. In cases of complete avulsion, there is no medical treatment. Indirect traumatic optic neuropathy was defined by Kashkouli as reduced best corrected visual acuity (BCVA), colour vision, positive relatively afferent pupillary defect (RAPD) with normal fundus and optic nerve examination and no evidence of direct trauma to the optic nerve on CT scan [4].

The treatment of traumatic optic neuropathy is controversial. There is no study which could validate a particular management protocol of indirect traumatic optic neuropathy. Treatment of traumatic optic neuropathy with high dose methylprednisolone was widely embraced with the publication in 1990 of the results of the Second National Acute Spinal COrd Injury Study [29]. Lew et al. [30] investigated the effect of high-dose steroid therapy in traumatic optic neuropathy to detect changes in the blood flow of the disc, concluding that the steroid therapy improved the optic nerve head blood flow. As classified by Levin et al. methylprednisolone regimens include megadose $(>5,400 \mathrm{mg} / \mathrm{d})$, very high dose $(2,000-5,400$ $\mathrm{mg} / \mathrm{d})$, high-dose (500-1,999 mg/d), moderate dose (100-499 $\mathrm{mg} / \mathrm{d}$ ), and low-dose (below $100 \mathrm{mg} / \mathrm{d}$ ) treatment [31]. According to the findings of the International Optic Nerve Trauma Study released in 1999, it is suggested that treating traumatic optic neuropathy with high-dose corticosteroids may be harmful [32], higher risk of death was reported by Roberts et al. [33] after administration of high dose corticosteroids. In the past few years, results of medical and surgical interventions have shown to be uncertain. Three types of indirect traumatic optic neuropathy managements have been reported (steroids, optic canal decompression, and observation). The International Optic Nerve Trauma Study showed no significant benefit of steroid and/or surgical decompression compared with observation [30].

There is absence of widespread human experimentation because of the risk of potential harm. Emanuelli et al. [34] in 2015 suggested a treatment approach consisting of intravenous steroid treatment (within 8 hours of injury) and endoscopic surgical decompression. Reports of no significantly better visual outcome after corticosteroid and/or optic canal decompression surgery were presented in the past years [35]. Although the complications of steroid treatment are rare, there is no convincing evidence that steroid treatment provides any benefits in terms of improvement of visual acuity in patients with traumatic optic neuropathy. Individual circumstances may require the use of corticosteroids in traumatic optic neuropathy. Based on admittedly limited data, anti-inflammatory doses of corticosteroids (e.g., oral prednisolone $60-100 \mathrm{mg} /$ day) are likely safe in this setting. In the abcence of better information, it seems prudent to limit such treatments to $1 \mathrm{mg} / \mathrm{kg}$ of methylprednisolone every $6 \mathrm{~h}$. This should be not misinterpreted as a treatment of traumatic optic neuropathy [36].

A new treatment option for traumatic optic neuropathy is the cytokine hormone erythropoietin (EPO) [37]. EPO has been reported to be effective for reducing neural apoptosis and protecting ischaemic brain injury [38]. A pilot study of intravenous EPO for traumatic optic neuropathy showed a promising result [37].

\section{CONCLUSIONS}

A rare scenario among optic nerve injuries is the avulsion of the optic nerve. In our case presented we found the complete form of avulsion. Our case is an example for the use of multimodal imaging, which can be helpful to establish the diagnosis of a rare injury. In traumatic cases where the injury in the orbital region is combined with visual loss, concerning the circumstances of the injury as well, we have to think of damage of the optic nerve, even in cases of trivial, blunt impact.

Authors' contribution: AG: writing the manuscript, clinical examination. SG: reviewing the manuscript, clinical followup examinations, performing OCT and fundus images. BC: reviewing the manuscript, clinical examination, performing the ultrasound examination. ZR: reviewing the manuscript, clinical examination. GR: performing magnetic resonance imaging. ZZN: reviewing the manuscript, clinical examination. EM: reviewing the manuscript, clinical follow-up examinations.

Ethical approval: Case presentation was conducted in accordance with the Declaration of Helsinki and according to requirements of all applicable local and international standards.

Conflicts of interest/funding: The authors declare no conflict of interest. No financial support was received for this study.

The case was presented at EPOS Annual Meeting 2018 in Budapest.

\section{REFERENCES}

1. Vilensky J, Robertson W, Suarez-Quian C editors. The clinical anatomy of the cranial nerves: the nerves of "On Olympus Towering Top”. Ames, Iowa: Wiley-Blackwell; 2015.

2. Selhorst JB, Chen Y. The optic nerve. Semin Neurol 2009;29:29-35. https://doi.org/10.1055/s-0028-1124020.

3. Salzmann M. Die Ausreißung des Sehnerven (Evulsio nervi optici). Z Augenheilk 1903;9:489-505.

4. Kashkouli MB, Yousefi S, Nojomi M, Sanjari MS, Pakdel F, Entezari $\mathrm{M}$, et al. Traumatic optic neuropathy treatment trial (TONTT): open label, phase 3, multicenter, semi-experimental trial. Graefes Arch Clin Exp Ophthalmol 2018;256:209-18. https://doi.org/10. 1007/s00417-017-3816-5.

5. Gross CE, DeKock JR, Panje WR, Hershkowitz N, Newman J. Evidence for orbital deformation that may contribute to monocular blindness following minor frontal head trauma. J Neurosurg 1981; 55:963-6. https://doi.org/10.3171/jns.1981.55.6.0963. 
6. Lister W. Some concussion changes met with in military practice. Br J Ophthalmol 1924;8:305-8. https://doi.org/10.1136/bjo.8.7.i1.

7. Sanborn GE, Gonder JR, Goldberg RE, Benson WE, Kessler S. Evulsion of the optic nerve: a clinicopathological study. Can J Ophthalmol 1984;19:10-6.

8. Hykin PG, Gardner ID, Wheatcroft SM. Optic nerve avulsion due to forced rotation of the globe by a snooker cue. Br J Ophthalmol 1990;74:499-501. https://doi.org/10.1136/bjo.74.8.499.

9. Williams DF, Williams GA, Abrams GW, Jesmanowicz A, Hyde JS. Evulsion of the retina associated with optic nerve evulsion. Am J Ophthalmol 1987;104(1):5-9. https://doi.org/10.1016/00029394(87)90285-6.

10. Park JH, Frenkel M, Dobbie JG, Choromokos E. Evulsion of the optic nerve. Am J Ophthalmol 1971;72:969-71. https://doi.org/10. 1016/0002-9394(71)91699-0.

11. Steinsapir KD, Goldberg RA. Traumatic optic neuropathy. Surv Ophthalmol 1994;38:487-518. https://doi.org/10.1016/00396257(94)90145-7.

12. Schlenker T, Apenberg S, Raedsch R, Andrassy K, Plachky J, Kommerell B. Antineutrophile zytoplasmatische Antikörper bei chronisch-entzündlichen Darmerkrankungen [Antineutrophil cytoplasmic antibodies in chronic inflammatory bowel diseases]. Dtsch Med Wochenschr 1992;117:1463-8. https://doi.org/10.1055/s-20081062465 [Article in German].

13. Spizziri LJ. Avulsion of optic nerve. Report of a case. Am J Ophthalmol 1964;58:1056-9. https://doi.org/10.1016/0002-9394(64) 90020-0.

14. Anderson RL, Panje WR, Gross CE. Optic nerve blindness following blunt forehead trauma. Ophthalmology 1982;89:445-55. https://doi.org/10.1016/s0161-6420(82)34769-7.

15. Buchwald HJ, Otte P, Lang GE. Evulsio nervi optici nach stumpfem Bulbustrauma-Fallbericht und Literaturübersicht [Evulsion of the optic nerve following blunt bulbar trauma. Case report and review of the literature]. Klin Monbl Augenheilkd 2003;220:303-8. https:// doi.org/10.1055/s-2003-39425 [Article in German].

16. Brodsky MC, Wald KJ, Chen S, Weiter JJ. Protracted posttraumatic optic disc swelling. Ophthalmology 1995;102:1628-31. https://doi. org/10.1016/s0161-6420(95)30817-2.

17. Hidasi V, Kolozsvari L, Rigo G. Evulsio nervi optici. Szemészet 1989;126:178-81. [Article in Hungarian].

18. Frost WA. Trans Ophthal Soc U.K. 1903 23:286.

19. Stanton-Cook L. Injury simulating congenital anomaly. Br J Ophthalmol 1953;37:188-9. https://doi.org/10.1136/bjo.37.3.188.

20. Singh J, Goyal JL, Garg SP. Optic nerve avulsion following tip-cat injury, fluorescein angiographic and echographic features. AfroAsian J Ophthalmol. 1987;6:71-3.

21. Chow AY, Goldberg MF, Frenkel M. Evulsion of the optic nerve in association with basketball injuries. Ann Ophthalmol 1984;16: $35-7$.

22. Fard AK, Merbs SL, Pieramici DJ. Optic nerve avulsion from a diving injury. Am J Ophthalmol 1997;124:562-4. https://doi.org/10. 1016/s0002-9394(14)70879-7.

23. Yokoyama R, Kubota M, Kandatsu A, Ueoka Y, Horiuchi T. A case od avulsion of the disc. Jpn J Clin Ophthalmol 1985;39:111-5.
24. Hillman JS, Myska V, Nissim S. Complete avulsion of the optic nerve. A clinical, angiographic, and electrodiagnostic study. Br J Ophthalmol 1975;59:503-9. https://doi.org/10.1136/bjo.59.9.503.

25. Tsai HH, Jeng SF, Lin TS, Kueh NS, Hsieh CH. Predictive value of computed tomography in visual outcome in indirect traumatic optic neuropathy complicated with periorbital facial bone fracture. Clin Neurol Neurosurg 2005;107:200-6. https://doi.org/10.1016/j. clineuro.2004.07.015.

26. Foster BS, March GA, Lucarelli MJ, Samiy N, Lessell S. Optic nerve avulsion. Arch Ophthalmol 1997;115:623-30. https://doi.org/10. 1001/archopht.1997.01100150625008.

27. Mahapatra AK. Visual evoked potentials in optic nerve injury. Does it merit a mention? Acta Neurochir (Wien) 1991;112:47-9. https:// doi.org/10.1007/BF01402453.

28. Mahapatra AK. Delayed recovery from indirect optic nerve injury. A report of two unusual cases. J Neurosurg Sci 1992;36:151-3.

29. Bracken MB, Shepard MJ, Collins WF, Holford TR, Young W, Baskin DS, et al. A randomized, controlled trial of methylprednisolone or naloxone in the treatment of acute spinal-cord injury. Results of the Second National Acute Spinal Cord Injury Study. N Engl J Med 1990; 322:1405-11. https://doi.org/10.1056/NEJM199005173222001.

30. Lew H, Lee SY, Jang JW, Kim HY, Kang SJ, Kim SJ. The effects of high-dose corticosteroid therapy on optic nerve head blood flow in experimental traumatic optic neuropathy. Ophthalmic Res 1999;31: 463-70. https://doi.org/10.1159/000055572.

31. Levin LA, Beck RW, Joseph MP, Seiff S, Kraker R. The treatment of traumatic optic neuropathy: the international optic nerve trauma study. Ophthalmology 1999;106:1268-77. https://doi.org/10.1016/ s0161-6420(99)00707-1.

32. Steinsapir KD. Treatment of traumatic optic neuropathy with highdose corticosteroid. J Neuroophthalmol 2006;26:65-7. https://doi. org/10.1097/01.wno.0000204646.94991.68.

33. Roberts I, Yates D, Sandercock P, Farrell B, Wasserberg J, Lomas G, et al. CRASH trial collaborators. Effect of intravenous corticosteroids on death within 14 days in 10008 adults with clinically significant head injury (MRC CRASH trial): randomised placebo-controlled trial. Lancet 2004;364:1321-8. https://doi.org/10.1016/S0140-6736(04)17188-2.

34. Emanuelli E, Bignami M, Digilio E, Fusetti S, Volo T, Castelnuovo P. Post-traumatic optic neuropathy: our surgical and medical protocol. Eur Arch Otorhinolaryngol 2015;272:3301-9. https://doi. org/10.1007/s00405-014-3408-5.

35. Singman EL, Daphalapurkar N, White H, Nguyen TD, Panghat L, Chang J, et al. Indirect traumatic optic neuropathy. Mil Med Res 2016;3:2. https://doi.org/10.1186/s40779-016-0069-2.

36. Steinsapir KD, Goldberg RA. Traumatic optic neuropathy: an evolving understanding. Am J Ophthalmol 2011;151:928-33. https://doi.org/10.1016/j.ajo.2011.02.007.

37. Kashkouli MB, Pakdel F, Sanjari MS, Haghighi A, Nojomi M, Homaee $\mathrm{MH}$, et al. Erythropoietin: a novel treatment for traumatic optic neuropathy-a pilot study. Graefes Arch Clin Exp Ophthalmol 2011;249:731-6. https://doi.org/10.1007/s00417-010-1534-3.

38. Ghezzi P, Brines M. Erythropoietin as an antiapoptotic, tissueprotective cytokine. Cell Death Differ 2004;(Suppl. 1):S37-44. https://doi.org/10.1038/sj.cdd.4401450.

Open Access. This is an open-access article distributed under the terms of the Creative Commons Attribution 4.0 International License (https://creativecommons.org/ licenses/by/4.0/), which permits unrestricted use, distribution, and reproduction in any medium, provided the original author and source are credited, a link to the CC License is provided, and changes - if any - are indicated. (SID_1) 